\title{
Some observations on the mating behaviour of captive American pine martens Martes americana
}

\author{
Judith GRANT and Alex HAWLEY*
}

\begin{abstract}
Grant J. and Hawley A. 1996. Some observations on the mating behaviour of captive American pine martens Martes americana. Acta Theriologica 41: 439-442.

Four male and 8 female captive pine martens Martes americana (Turton, 1806) were observed for signs of mating. Behavioural changes associated with the breeding season began in mid-June. Subjective observation indicated that the frequency of abdominal scent marking and body contact between males and females increased from June through July and decreased during August. Aggression between females increased markedly during the breeding season. The animals emitted diverse vocalizations, including a throaty chuckle that was associated with breeding and that was indistinguishable by observers from a call emitted when females appeared to be consoling young kits. Copulation was observed on 4 occasions during July in one pair of martens, and was typical of that described for Martes species in general. Two individual copulatory acts were timed and lasted 5 and $14.5 \mathrm{~min}$, respectively. The female appeared to control the timing and duration of copulation and seemed in one instance to actively solicit the attention of the male.
\end{abstract}

Nova Scotia Agricultural College, Box 550, Truro, Nova Scotia, Canada, B2N 5E3

Key words: Martes americana, mating, behaviour, copulation

\section{Introduction}

Research by Hawley et al. (1993) directed at developing a housing and management system for captive pine martens Martes americana (Turton, 1806) provided an opportunity to observe reproductive behaviour in this species. Lodé (1991) described in detail the mating behaviour of stone martens $M$. foina and several authors (Ashbrook and Hanson 1930, Brassard and Bernard 1939, Markley and Bassett 1942, Cochrane 1991) have provided a general description of breeding behaviour of American pine martens. The present communication contributes to our knowledge of copulation and other behaviours of captive pine martens during the breeding season.

\section{Animals and methods}

Four wild-caught male, 5 wild-caught female and 3 captive-born female martens were used in this study, conducted at the Nova Scotia Agricultural College, Truro. Wild-caught animals had been trapped in February 1990. The captive-born females were born in April 1990 to one of the wild-caught

\footnotetext{
*Current address: University of Northern British Columbia, 3333 University Way, Prince George, B.C., Canada, V2N 4Z9. Reprint requests should be sent to A. Hawley.
} 
females. Martens were housed in four outdoor pens and observed from June to September 1992. Each pen was approximately $225 \times 140 \times 21 \mathrm{~cm}$ and housed two female and one male martens. Housing and management were as described by Hawley et al. (1993). The martens were observed as opportunity provided and descriptive observations made of the animals' breeding behaviour. This amounted to non-systematic observation of the animals 5 days per week at variable times between 07.00 and 17.00 . Individual observation periods lasted from several minutes to an hour.

\section{Results and discussion}

Behavioural changes associated with the breeding season were first observed in mid-June. Social interaction was characterized by a shift from indifference or avoidance among all individuals, to interest and courtship between males and females, and aggression between females. Markley and Bassett (1942) reported that female pine martens became antagonistic toward each other during the breeding season. In the present study, inter-female aggression became so intense in one pair that the subordinate female received several bite wounds from the dominant female. In another pen, the subordinate female became thin, weak and dehydrated, apparently as a result of harassment by the dominant female (the subordinate female recovered completely when isolated from the dominant female). In both cases, the subordinate female was removed, the dominant female successfully mated and whelped a litter, and the subordinate female did not reproduce. In the two other pens, in which antagonism between females was less pronounced, females remained paired throughout the breeding season, no mating was observed, and no litters were whelped. Thus, the more extreme aggression displayed by two of the females was associated with their subsequent pregnancy. It is unknown if the association between extreme aggression and pregnancy was the result of the occurrence of estrus in some females and not in others.

The frequency of abdominal scent marking was observed to increase in mid-June, reached a peak in July, and decreased during August. Scent markings were conducted as part of extensive movements around the pen. Individual markings lasted only a few seconds as animals passed over poles, logs and feeders. In contrast, stone martens were observed to scent mark the ground for periods lasting a few minutes (Lodé 1991).

The martens used a variety of vocalizations. Belan et al. (1978) reported that wild martens used several variations of a "chuckle" while held in live traps and associated these with either agonistic or distress behaviour. Males and females in the present study used a characteristic throaty chuckle during the breeding season which was not used between adults at other times of the year. The call appeared to be lower in pitch and of longer duration than the nervous chuckle used by martens when frightened. This vocalization is probably the "love call" identified for pine martens by Adams (1962) and Strickland et al. (1982) and may be analogous to the "muted cluck" described by Lodé (1991) for stone martens. Lodé (1991) suggested that this vocalization may function to reduce conspecific ag- 
gression in order to facilitate copulation. In the present study, the throaty chuckle was also used by females with young after the animals were disturbed by the weighing of kits. This suggests that the same or a similar vocalization may also function to calm or console young.

The frequency with which martens were observed to come into physical contact with each other increased markedly during July. During this period, individuals would spend considerable time resting in the same nestbox or on the floor of the pen in close proximity to each other, often maintaining some form of body contact. The most overt of these contacts involved animals dragging their abdomens over one another as if scent marking the other animal. This type of behaviour was observed only during July and may be an essential part of courtship. The variety and duration of precopulatory behaviour reported by several authors for pine martens suggest that this species has a long and involved courtship.

Copulation was observed 4 times in a single pair of pine martens, once on July 15 , once on July 16 and twice on July 22 . The female was 27 months old and was captive-born. All observed copulations occurred between 07.10 and $11.00 \mathrm{~h}$. The durations of two of these copulations were accurately recorded and were 5 and $14.5 \mathrm{~min}$, respectively. This represents a copulatory act of much shorter duration than previously described for pine martens (Strickland et al. 1982, Strickland and Douglas 1987), stone martens (Lodé 1991) and mustelids in general, but longer than the copulatory acts of free-ranging pine martens described by Henry and Raphael (1989). Conditions of confinement may have contributed to these differences among studies.

It is uncertain whether short copulatory acts result in impregnation. Multiple copulations may be required for induction of ovulation in this species (Mead 1994). In the present study, the observer was visible to the martens and this may have affected the duration of copulation. Also, copulations of longer duration may have occurred at times when the martens were unobserved. In the present study, animals were observed only during daylight hours. Martens are known to also be active in the evening or during the night (Strickland et al. 1982).

Markley and Bassett (1942) and R. L. Cochrane (unpubl.) attributed considerable control of the initiation of copulation to the male marten. In the present study, the female appeared to control the timing and duration of copulation by her response to the male's advances and could easily prevent consummation of mating if she was unreceptive. The screaming and snarling accompanying mating and the short duration of copulatory acts described by Henry and Raphael (1989) may have been the result of a male's attempt to mate an unreceptive female. In contrast, in one instance in the present study, the female appeared to actively solicit the attention of the male by repeatedly entering his nestbox until he emerged and followed her to the floor where they mated.

The posture of the martens during copulation was typical of mustelids and was similar to that described by R. L. Cochrane (unpubl.) for pine martens and Lodé (1991) for stone martens. When intromission was apparently successful, copulation 
was marked by periodic shudders of the male's body lasting several seconds and occurring at 10 to $20 \mathrm{sec}$ intervals. This characteristic was not described by Lodé (1991) for stone martens and may be distinct to pine martens. During copulation, the pair moved slowly around the floor of the pen with the male emitting muted growls and the female emitting occasional muted screams. Copulation ended suddenly, usually with a brief and mild scuffle. Both animals remained on the floor grooming their pelvic region for approximately $1 \mathrm{~min}$ after copulation. The female, but not the male, spent several additional minutes rolling on the floor of the pen before returning to the nestbox. Post-coital rolling by the female is characteristic of stone martens (Lodé 1991).

The females stopped displaying mating behaviour around the end of July. The male continued to show interest in the female, but all observed attempts at mounting or close physical proximity of the male to the female were repulsed by the female.

\section{References}

Adams L. H. 1962. Mink raising. A. R. Harding Publishers, Columbus: 193-215.

Ashbrook F. G. and Hanson K. B. 1930. The normal breeding season and gestation period of marten. United States Department of Agriculture Circular 107: 1-7.

Belan I., Lehner P. and Clark T. 1978. Vocalizations of the American pine marten (Martes americana). Journal of Mammalogy 59: 871-874.

Brassard J. A. and Bernard R. 1939. Observations on breeding and development of marten (Martes americana). Canadian Field Naturalist 53: 15-21.

Cochrane R. L. 1991. Observations on reproduction in caged marten. [In: Abstracts of Presentations of Symposium on the Biology and Management of Marten and Fishers, 29 May-1 June 1991, Laramie].

Hawley A. W. L., Grant J. D. and Rankin M. A. 1993. Environmental requirements of captive pine marten (Martes americana). [In: Abstracts of Presentation of International Union of Game Biologists XXI Congress, 15-20 August 1993, Halifax]. Poster presentation.

Henry S. E. and Raphael M. G. 1989. Observations of copulation of free-ranging American marten. Northwest Naturalist 70: 32-33.

Lodé T. 1991. Conspecific recognition and mating in stone marten Martes foina. Acta Theriologica 36 : $275-283$.

Mead R. A. 1994. Reproduction in Martes. [In: Marten, sables and fishers: biology and conservation. S. W. Buskirk, A. S. Harestad, M. G. Raphael and R. A. Powell, eds]. Cornell University Press, Ithaca: 404-422.

Markley M. H. and Bassett C. F. 1942. Habits of captive marten. American Middland Naturalist 28: $605-616$.

Strickland M. A. and Douglas C. W. 1987. Marten. [In: Wild furbearer management and conservation in North America. M. Novak, J. A. Baker, M. E. Obbard and B. Malloch, eds]. The Ontario Trappers Association, North Bay: 530-546.

Strickland M. A., Douglas C. W., Novak M. and Hunzinger H. P. 1982. Marten. [In: Wild mammals of North America: biology, management, and economics. J. A. Chapman and G. A. Feldhammer, eds]. John Hopkins University Press, Baltimore: 599-612. 